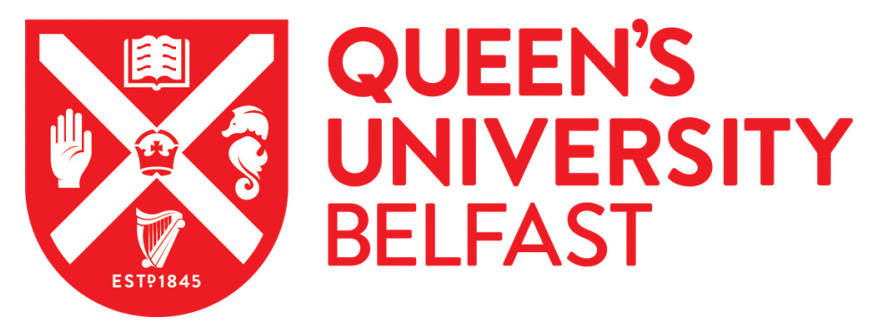

\title{
Commonalities and Differences in Social Work with Learning Disability and Child Protection: findings from a UK 'Burnout' national survey
}

McFadden, P., Manthorpe, J., \& Mallett, J. (2017). Commonalities and Differences in Social Work with Learning Disability and Child Protection: findings from a UK 'Burnout' national survey. British Journal of Social Work. https://doi.org/10.1093/bjsw/bcx070

Published in:

British Journal of Social Work

Document Version:

Peer reviewed version

Queen's University Belfast - Research Portal:

Link to publication record in Queen's University Belfast Research Portal

Publisher rights

(C) 2017 The Authors. This work is made available online in accordance with the publisher's policies. Please refer to any applicable terms of use of the publisher.

\section{General rights}

Copyright for the publications made accessible via the Queen's University Belfast Research Portal is retained by the author(s) and / or other copyright owners and it is a condition of accessing these publications that users recognise and abide by the legal requirements associated with these rights.

Take down policy

The Research Portal is Queen's institutional repository that provides access to Queen's research output. Every effort has been made to ensure that content in the Research Portal does not infringe any person's rights, or applicable UK laws. If you discover content in the Research Portal that you believe breaches copyright or violates any law, please contact openaccess@qub.ac.uk. 


\section{Commonalities and Differences in Social Work with Learning Disability and Child Protection: findings from a UK 'Burnout' national survey}

\section{Abstract}

Social work with adults with learning disabilities or intellectual disability may be organised as a discrete or specialist area of practice in the United Kingdom (UK). Little is known about contemporary social work practitioners' views of their work with adults with learning disabilities and if these differ from those of social workers in practice with different user groups or working in other specialities. This paper reports findings from a national survey of UK social workers undertaken in 2015 that measured burnout using the Maslach Burnout Inventory, across three domains, emotional exhaustion, depersonalisation and personal accomplishment. A total of 1359 social workers responded to the invitation to participate, of whom 77 reported predominantly working with adults with learning disabilities and 358 reported working in child protection social work. Comparisons are drawn between responses from social workers working in these distinct practice areas showing high levels of emotional exhaustion co-existing with high levels of personal accomplishment in both areas of practice. Other important distinctions and similarities are reported.

Key Words: Burnout, Child Protection Learning Disability, Social Work

\section{Introduction}

The International Federation of Social Workers (IFSW) in its policy statement on disability acknowledged that social workers work with people with a learning disability, their families and with communities, both domestically and internationally: 'Our work in these spheres encompasses, direct practice, group work, community development, policy practice, research and advocacy... Social workers work alongside people with disabilities and families to realise social inclusion, community living, employment, family support, and rehabilitation' (IFSW, 2012). The potential for social workers to make a difference in this area of practice is suggested by the subtitle of a social work textbook 'Social Work Practice with Intellectual Disability: Working to Support Change' (Bigby \& Frowley, 2009) and the claim reported by Horner (2012, p. 55) that many commentators view social work with people with learning disabilities as the 'high water mark' of the profession in terms of its confidence and skills to advocate and develop a vision of good care for people with 
learning disabilities. In a small study of social workers contributing to a multidisciplinary learning disability team in England (mainly consisting of healthcare professionals), Herod \& Lymbery (2002) reported social workers' role in challenging others' practice was valued by their colleagues.

The emphasis of the current paper is to draw comparisons between levels of burnout expressed by social workers working in adult learning disability, a group about which little is known in relation to their job and profile, and off-set these findings by comparison with the responses of child protection social workers within the same survey. Child protection was selected due to the contrasting high level of research about burnout in this area of practice by comparison to the dearth of research about learning disability social work. 'Burnout' is a yard-stick that has been the visible and valid subject of research in the human services for over four decades as it relates to problems with work itself, with intention to leave the job or the profession, and to images of the profession. A recent systematic review (Skirrow \& Hatton, 2007) concluded that burnout was a useful concept in measuring distress among workers in intellectual impairment practice arenas.

While social work with people with learning disability has a lengthy history, often associated with long-stay institutions (House of Commons, 1991), there is surprisingly little research on the current nature and effectiveness of the professional role with this user group in England. This may be because numbers overall are small and because social work practice in this area is sometimes subsumed by care management, the predominant form of organisational practice with adults in the United Kingdom (UK) since 1993 (Cambridge, 2008). While the new context of personalisation may be changing this role (Duffy, 2010) the social work contribution to care management continues. The advent of new legal duties in England and Wales such as the Mental Capacity Act 2005 has provided some new roles for social workers in supporting decisions for people who lack capacity to make or communicate their decisions. These have been scrutinised - although this much of this legislation is only applicable to a minority of individuals with learning disabilities (Williams et al 2014). New legislative frameworks such as the Care Act 2014 (England) and the Social Services and Well-being (Wales) Act 2014 (Wales) have 
not been specifically researched to assess their impact on practice with people with learning disabilities although there are inherent promises from both Acts' emphases on well-being, choice and control (see Parkin 2016; Welsh Government 2015). In Scotland (Hunter and Rowley 2015) a similarly broad pattern of social work engagement with people with learning disabilities is evident but again the evidence about their practice is sparse.

This lack of evidence is surprising for while the numbers of social workers employed by local councils to work with adults in the UK are not as high as those working with children or other user groups, they are not insignificant. Those recorded as working with adults currently stand at 16,100 social work jobs in English social services departments, $80 \%$ being female, their average age 45 years, with $79 \%$ from White and $21 \%$ from Black and minority ethnic groups (HSCIC, 2016). In Wales, workforce figures are complicated by the statistical collection methods used, since the figures on social work services for adults include occupational therapists and support workers as well as social workers, leading to an unexpected high number of 14,799 in total (Welsh Government, 2015); and the inclusion of trainees (total 3,645) is further complicating. Overall for Wales a more accurate figure might be the number of team managers and social workers holding the professional qualification - 3,417 for all client groups. In Scotland there are 11,012 registered social workers (Scottish Social Services Care 2016). Northern Ireland's 4128 social workers mostly (3000) work in statutory services. Additionally, 300 work in the criminal justice sector, guardian ad litem and education welfare services, 500 in the voluntary sector, with small numbers working independently (Department of Personal Social Services, 2006).

Despite these numbers the professional experiences of learning disability social workers appear comparatively neglected. This stands in contrast to the interest in collecting data about child protection social workers' staffing complements, morale and wellbeing (McFadden et al., 2014) and in practice areas such as mental health social work (Evans, et al., 2005). In these sections of the profession there is interest in particular on the generic risks of burnout leading to exit from the profession or suboptimal practice (Healy, et al., 2009; Gibbs, 2009). Some studies have examined the relationship between burnout, informal social support and psychological distress 
among social workers but many do not distinguish between social work practice areas. For example, a study of Spanish social workers $(n=189)$ found a high incidence of psychological distress and burnout, especially Emotional Exhaustion $(E E)$, but it is unclear if any participants worked with people with learning disabilities (Sanchez-Moreno, et al., 2014).

Studies conducted within the learning disability sector do not provide much insight into social workers' burnout or work related stressors and enjoyment. The reasons for this are two-fold; first most focus on the wider health and care workforce among whom social workers are few and rarely separately identified. Dyer \& Quine's (1998) study of occupational stress among National Health Service (NHS) direct care staff, for example, was of non-professionals. A survey of 108 Australian learning disability community support workers (Vassos \& Nankervis 2012; 2013) similarly covered these non-professionals' burnout. Smyth, et al., (2015) examined perceived stress, burnout, and job commitment among 139 UK disability support workers (not social workers) and an apparently similar staff group (direct support professionals) was surveyed in Canada (Hickey, 2014). In a Dutch community residential service for people with mental health problems, those surveyed about intention to leave included 37 social workers among 208 respondents (Geurts, et al., 1998) but did not distinguish findings by profession.

Second, many learning disability workforce studies have been conducted in residential facilities, such as group homes or specialist units (eg Harries et al.'s 2015 study of Australian support workers), or in practice focussing on particular needs or circumstances (eg Leyin \& Wakerly's (2007) study of staff challenging behaviour services and Lundström, et al.'s (2007) study of those exposed to workplace violence). In these settings social workers are infrequently employed (see Kozak, et al.'s, 2013 study of German residential facilities where only $9 \%$ of respondents were social workers).

Child protection social work is widely viewed as one of the most challenging areas of practice with high levels of burnout and turnover (McFadden et al, 2014; Hussein, et al., 2014a; 2014b). Pressure on child protection social work has increased with a 
litany of Serious Case Reviews alleging failure on the part of social workers in preventing child abuse and child death tragedies (Jones, 2014) (SCRs have also focussed on failings in the care and safeguarding of adults with learning disabilities see Manthorpe and Martineau 2015). A government-backed review of child protection called for 'a system which was more child centred and about learning rather than compliance and blaming' (Munro, 2011, p.93) and for emphasis to be placed on 'do(ing) the right thing' rather than 'doing things right'. However, five years on, there is little evidence that these changes have materialised or that the context of child protection social work has been addressed. Several reports on social workers' burnout have linked it to uncertainties and pressures related to their professional role and organisational context, although there is also interest in shifting the focus on the deficiencies of the role to exploring social workers' resilience (Russ, et al., 2009).

\section{Definitions and Theory}

In this paper we use the term 'learning disability' as defined in 'Valuing People, A New Strategy for Learning Disability for the 21st Century' (Department of Health, 2001) (in countries outside the UK the term intellectual impairment is more commonly used). While adult social workers may work with adults with learning disability and their families as recipients of care management, personal budgets, or social care services, some social workers have specialist interest or roles in this client or user group. This may stem from organisational models of social work services, where social workers may work as part of a multi-professional team undertaking assessments or reviews, or as specialists supporting people with complex care needs and changing circumstances, or about whom there are concerns about their safeguarding, mental, and physical wellbeing. Child protection social work is defined as having the statutory responsibility for safeguarding and protecting children from abuse, neglect and 'significant harm' as defined in legislation on child protection (e.g The Children Act 1989 (England) or The Children Order 1995 (Northern Ireland) and other similar legislation in Scotland and Wales). These social workers have a duty to respond to and investigate concerns relating to children and families. The role is challenging, highly accountable and associated with high levels of burnout and workforce retention problems (McFadden et al, 2014). This is different 
from those social workers categorised as working with children 'in need'. Section 17 of the Children Act (1989) defines a child as being 'in need' if they are unlikely to achieve or maintain a standard of health and development without intervention of social services or if health or development would be significantly impaired without such intervention; or if a child has a disability. The 'child protection' category is also different from 'looked after children' who are not in the care of their family of origin but, instead, are 'looked after' by social services in alternative 'out of home' foster placement or children's homes.

\section{Methods}

This study reports an online cross-sectional UK wide survey of social workers in practice that included questions relating to social worker roles, length of experience, service area, supervision effectiveness and frequency, workload, workload weighting, caring responsibilities, practice teaching role and also included a measure of burnout using the Maslach Burnout Inventory to measure Emotional Exhaustion, Depersonalisation and Personal Accomplishment (see McFadden 2015). This present paper compares adult learning disability and child protection social workers' responses to Maslach Burnout Inventory (MBI) items to measure levels of burnout across three domains.

\section{Burnout Definition and Measurement Tool}

Maslach (1982) acknowledges a range of definitions of 'burnout'; some being based on causal explanations - others referring to the individual impact of burnout. Maslach \& Jackson (1986) offer the following definition:

"A syndrome of emotional exhaustion, depersonalization, and reduced personal accomplishment that can occur among individuals who do "people work" of some kind. . . . Burnout can lead to deterioration in the quality of care or service provided." (Maslach \& Jackson, 1986:1).

The Maslach Burnout Inventory - Human Services Survey (MBI-HSS referred to as 'MBI' subsequently; see Table 1) measures the three elements of emotional exhaustion (EE) comprising 9 items, depersonalisation (DP) comprising 5 items and reduced personal accomplishment (PA) comprising 8 items. EE is a loss of energy 
for one's job, DP is a loss of feeling or a reduced capacity for empathy towards service users and reduced PA is a loss of a feeling of satisfaction with work. A total of 22 items measure these domains and participants are required to report frequency of experienced feelings and thoughts on each item using a Likert scale ranging from (0) Never to (6) Every Day. Item scores are summated to produce scale scores for each respondent. These scales measure an individual's experience on a continuum between aspects of burnout and job engagement. Job engagement is conceptualised as the opposite of burnout (having energy, capacity for empathy and high personal accomplishment) and experiences of the job can run along a line of continuum between these positions (Maslach \& Leiter, 2008). Examples of questions for EE include 'I feel burned out from my job' and 'I feel at the end of my rope'. Questions for DP are 'I feel I treat some service recipients as impersonal objects' or 'I feel I that this job has hardened me emotionally'. EE and DP questions are negatively framed so responses of ' 0 ' mean that the person 'never' feels this way while ' 6 ' means they feel that way 'every day'. PA questions are positively framed with example questions being 'I feel exhilarated by working with service recipients' and 'I feel I make a positive difference in the lives of service recipients'. Here a ' 0 ' meaning 'never' is a concerning response, whereas ' 6 ' meaning 'every day' reflects a positive feeling about one's work. Maslach, et al., (1996) caution that the PA subscale is independent of the other two domains and is not the opposite of EE and DP.

\section{Reliability and Validity of the Maslach Burnout Inventory (MBI)}

In the development of the MBI-HSS the three factors identified through principal component analysis were replicated with various samples across a range of professions such as teachers, school psychologists, legal aid employees and therapists (Maslach et al 1996). Furthermore, confirmatory factor analysis found emotional exhaustion and depersonalisation to be distinct factors but more highly correlated with high levels of psychological strain than was personal accomplishment. Convergent validity of the MBI-HSS has been demonstrated by its developers who examined whether individual MBI scores are correlated with behavioural ratings (made independently by a third party who knew the individual well). 
Many MBI-HSS studies have shown that scale reliabilities (using Cronbach's alpha coefficients) are usually well above 0.70 , except for some examples for the DP scale (Schaufelli, 2001). The ideal internal consistency of a scale has to be greater than 0.70 to show a reliable level of internal consistency of the measurement. In the current study the Cronbach's alpha level was .88 therefore we can conclude that internal consistency is at a reliable level.

Table 1: Items in the Maslach Burnout Inventory (MBI) INSERT TABLE 1 HERE

\section{Ethical Approval}

This study received ethical approval in March 2015 by the Office of Research Ethics Northern Ireland Committee. Participation information literature explained consent and risks and benefits of participation. For example, participants might risk exposure of poor practice by the nature of the questions around burnout such as 'I feel at the end of my rope' or 'I treat service recipients as impersonal objects'. Negatively framed questions were also balanced with positively framed PA questions, such as 'I feel exhilarated working closely with service recipients'. Individuals were assured that participation was irreversibly confidential but also given direction about seeking support if they felt that their practice might be compromised due to feelings of burnout.

\section{Findings}

The Sample

Non-probability sampling techniques were used. Readers of 'Community Care', a long-standing professional magazine for UK social workers, were offered an opportunity to participate in an anonymous UK-wide survey of social worker burnout as part of the publication's 'Standing up for Social Work' campaign. The survey was advertised through news stories on the website communitycare.co.uk and through email alerts to subscribers to the magazine's email lists throughout the month the survey remained open in summer 2015. 


\section{Sample Characteristics}

The total responses to this UK wide survey numbered 1,359. Child protection social workers made up 28\% (382 responses) of overall respondents. Other children's social workers described themselves as predominantly working with looked after children $(n=163)$, children in need $(n=44)$, or in disabled children's services $(n=52)$. For the purposes of the current paper, 'child protection social workers' are distinct from other child-focused social work services as the aim was to target those social workers who are responsible for the assessment and support of children at risk of significant harm that remain at home or are in the care of the local authority. This typically is the sector that is portrayed as being at most risk of stress and burnout (McFadden 2013). Respondents working with adults were as follows: older people's social workers consisted of $19 \%$ of the sample (254 responses); $10 \%$ mental health $(n=142), 6 \%$ adult learning disabilities $(n=77), 4 \%$ adult physical disabilities $(n=54)$ and $0.3 \%$ criminal justice $(n=4)$.

Most (89\%) respondents worked in England. Those working in Wales and Scotland constituted $5 \%$ of the sample respectively; while just over $1 \%$ of respondents were from Northern Ireland (30 participants did not identify their country). These descriptive findings relate to those who responded to the questions but some data were missing where answers were missing or incomplete.

Responses by gender were $83 \%$ women and $17 \%$ men. Female respondents were more likely than males to be carers but the difference was not substantial with $44 \%$ males and 53\% females reporting they had a caring role outside of their job. 'Caring role' included childcare. Response by age range in years was 18-25 (4\%), 26-35 (23\%), 36-45 (23\%), 46-55 (32\%) and 56+ (18\%). This means that there was an equal split of respondents who were under or over 45 years.

\section{INSERT FIGURE 1 HERE}

The 77 respondents working with adults with learning disabilities included 45 frontline social workers, 19 senior social workers, 7 first line managers, 2 social work assistants, 2 senior social services managers and a social work student (one did not state role). For ease of reading all are referred to as social workers. A total of 64 of 
the 77 adult learning disability social workers were women and 11 were men. Male respondents were typically older than females with $82 \%$ being aged 45 years or older. Female respondents were more evenly spread across age bands, with 36 (56\%) aged under 45 years and 27 (44\%) aged over 45 years. In relation to caring responsibilities, 35 of the 77 had a caring role (including childcare) outside of their job with women being nearly as likely to have a caring role outside of work as men. These proportions were very similar across the social workers responding to the survey regardless of user group focus.

Of the 382 child protection social workers, $86 \%$ were women and $14 \%$ men. Of those working at social worker and senior social worker grade $90 \%$ were women and $10 \%$ men. $83 \%$ of female child protection social workers were frontline managers versus $17 \%$ men. The ages of those working in child protection were approximately normally distribution, with a minority $(7 \%)$ being $18-25$ years, 36\% aged $26-35$ years, $24 \%$ aged $36-45$ years, $24 \%$ aged $46-55$ years and $9 \%$ aged 56 years and over.

\section{Employment}

More than half of the adult learning disability social workers had worked less than 5 years in their present job (62\%) while the remainder (38\%) had been more than 5 years in their current position. Levels of social work experience were reported as high, with 41 respondents (53\%) having up to 10 years' experience and 36 (47\%) possessing between 11 and 20 years' experience.

\section{INSERT FIGURE 2 HERE}

When compared to the wider sample of 1359 respondents, those working with people with learning disability seemed to be a more stable workforce in relation to time in post especially in contrast to those in child protection. The majority $(71 \%)$ in child protection social work had less than 10 years' experience. However, very few of those working with people with learning disability were in their early professional career. In child protection services $13 \%$ of respondents had been in their job less than one year compared to $4 \%$ of learning disability social work respondents. However, both sectors reported holding similar levels of tenure for 1-3 years in post 
(20\%), 3-4 years in post ( $16 \%$ child protection vs. $10 \%$ learning disability) and $4-10$ years in post $(22 \%$ child protection vs. $20 \%$ learning disability).

In relation to the practice sector, the majority of responding learning disability social workers worked in the statutory sector $(97 \%)$ with few $(3 \%)$ working in the voluntary sector and none in the private sector. This is similar for child protection social workers with $98 \%$ working in the statutory sector, $1.5 \%$ in the voluntary sector and $0.5 \%$ in private sector employment. Of those working with learning disability service users who were employed in the statutory sector, $28 \%$ were practice teachers/educators compared to $22 \%$ of those in child protection. The vast majority of adult learning disability and child protection respondents were UK qualified $(97 \%$ and $96 \%$ respectively).

\section{Caseloads and Supervision}

In relation to caseload, $96 \%$ of responding learning disability social workers reported holding less than 60 cases. Only $6 \%$ of learning disability respondents had case load weighting. Almost three quarters $(74 \%)$ said they did not have caseload weighting but the remainder $(20 \%)$ did not know if they had caseload weighting. In child protection caseloads were smaller; $31 \%$ had less than 10 cases $75 \%$ less than 20 cases and $86 \%$ less than 30 . One in five $(20 \%)$ reported caseload weighting and $60 \%$ said they did not have caseload weighting with $20 \%$ stating that they did not know if caseload weighting applied or not.

\section{INSERT FIGURE 3 HERE}

Overall three quarters $(76 \%)$ of learning disability and child protection respondents were managed by someone with a social work qualification. In relation to supervision, $55 \%$ in learning disability services received supervision monthly; another $34 \%$ reporting supervision every two to three months. In contrast, $70 \%$ of child protection social workers reported monthly supervision and $23 \%$ every two to three months. A minority of learning disability social workers (3\%) reported no supervision. While one in three (33\%) working with adults with learning disability considered their supervision was effective, almost one in five thought their supervision was ineffective (19\%). The remaining half $(48 \%)$ considered it sometimes effective. Similarly, $33 \%$ of child protection social workers thought supervision was effective but $27 \%$ said it was ineffective ( $41 \%$ said it was sometimes 
effective). Effective supervision was found to be related to levels of emotional exhaustion (EE) and depersonalisation (DP). Social workers reporting effective supervision, $60 \%$, also reported high EE. Conversely, among who reported that supervision was ineffective, this increased to $86 \%$. This suggests that the risk of experiencing high EE increases from 1:2 to 3:4 with ineffective supervision. Reports of high levels of DP were $24 \%$ when associated with effective supervision (1:4 risk) however, when supervision was reported as ineffective this increased to $35 \%(1: 3)$ (for further details see McFadden, 2015).

Levels of Burnout (Emotional Exhaustion, Depersonalisation and Personal Accomplishment)

Burnout was measured across the three domains of EE, DP and PA. High, Moderate and Low levels of these three domains are determined by 'cut off' points as indicated in Table 2. Combining these scores to form a single measure is not valid as they have not been designed to be computed or added to each other.

INSERT TABLE 2 HERE

\section{Learning Disability Social Work Levels of Burnout in contrast to Child Protection Social Work}

\section{Emotional Exhaustion (EE)}

This is expressed in statements about feeling over extended with one's work. High levels of EE, as categorised by Maslach et al.'s (1996) cut-off points, were reported by $69 \%$ of respondents working with adults with learning disabilities, compared to $75 \%$ of those working in child protection (see Table 3 ). Those reporting moderate levels of EE were $18 \%$ of both groups. Likewise, low EE was reported by $7 \%$ of respondents working in child protection while $13 \%$ of the adult learning disability group had low EE.

INSERT TABLE 3 HERE

\section{Depersonalisation (DP)}

High DP is the loss of feeling for service recipients/users and higher mean scores are associated with burnout. A total of $15.5 \%$ of responding social workers working 
with adults with learning disabilities scored highly in DP, compared to $32.4 \%$ of social workers in child protection. Child protection social workers' scores were almost evenly spread across low, moderate and high DP (Table 4). In summary, two thirds $(71 \%)$ of child protection social workers scored high DP whilst proportionately more of those working with adults with learning disability reported low levels of DP with almost half having low DP scores (46.5\%) That said, more than a third of those working in learning disability reported moderate levels of DP $(38 \%)$ with a minority reporting high DP (15.5\%).

\section{INSERT TABLE 4 HERE}

\section{Personal Accomplishment (PA)}

The PA subscale measures feelings of accomplishment, competence and success in work with clients or service users. Overall moderate to high levels of personal accomplishment (PA) scores were reported at 53\% for child protection social workers and $44 \%$ in learning disability social workers. Low levels of PA were reported in $47 \%$ child protection social workers and $56 \%$ of learning disability social workers (Table 5). High burnout is associated with low PA scores combined with high EE and DP, which is consistent with current findings on EE and DP in this study.

\section{INSERT TABLE 5 HERE}

\section{Discussion}

\section{Limitations of the study}

The limits of this survey are acknowledged. We do not know if the respondent sample was representative of the profession although the demographics of the respondent group working with adults with learning disabilities are similar to national statistics about social workers working with adults in English local councils and indeed to social workers working with children (Department for Education, 2015). The lack of data about specialist social workers in the UK means that our discussion is focused on the English context; moreover as there were few respondents in the 
learning disability group from countries other than England our analysis did not make comparisons by country.

As noted, this study is limited by the sampling method as this is based on selfselection non-probability techniques so the findings cannot be assumed to be generalisable. However, the sample size is sufficiently large to offer some level of insight into the profile and experiences of those who have participated. Furthermore, when assessing the risk of bias, those who have completed the survey may have been motivated by atypical negative or positive experiences. In assessing this risk, it should be noted that despite a high percentage of workers in both groups reporting high EE (child protection 75\% versus 69\% learning disability), less DP was reported among both groups (child protection $32.4 \%$ and $15.5 \%$ learning disability). In relation to PA, $47 \%$ of child protection workers and $56.3 \%$ of learning disability workers reported low PA. This means that almost half of the respondents reported high PA despite larger percentages reporting high EE scores in both groups. The MBI has been found to be statistically reliable and valid which is a firm strength of this survey. Test-retest reliability is described as stable over time by many studies that employed complex statistical methods using linear structural equations modelling (for example, Schaufelli, 2001). The main limitation in the use of the MBI with social workers may be that some of the questions pose major value conflict with regard to ethics and principles of social work and therefore there is a risk of social desirability bias (Maslach, et al., 1996, p. 16). This would mean that participants may have felt more inclined to provide 'acceptable' answers versus 'true' responses to the EE and DP questions. Addressing this potential risk, information to potential respondents clearly explained the need for honest responses and the strict confidential nature of data handing and analysis. The stated anonymity offered to respondents at the recruitment stage should have served to reduce the possibility of biased responding, however, one can never be absolute about the exclusion of social desirability bias.

\section{The findings}


The main survey findings suggest that it is not necessarily the case that child protection social workers have particularly and consistently experienced high levels of EE (see Table 3) and undertake an inevitably more challenging aspect of practice. Any depletion of emotional resources, leading workers to feel unable to give of themselves at a psychological level, may affect any or all service users but also carers and colleagues. While child protection social workers did score higher in EE, there were indications that some social workers in adult learning disability work are experiencing practice as difficult and this should not be over-looked. Likewise, while there were sharp contrasts in respect of feelings of DP (see Table 4), a minority of social workers working with adults with learning disabilities were negative about their work and seemed to be at great risk of expressing cynical attitudes and feelings about service users (as captured by the DP measures). This is concerning given the often distinct vulnerability of this service user group and the need for empathy and the promotion of personhood to be central to interventions (see Hunter and Rowley 2015). In respect of PA (evaluating oneself positively or negatively, particularly with regard to work with clients) results support the notion that many social workers find their work personally rewarding despite high levels of EE. Another important finding relates to how supervision perceived as 'effective' can impact on levels of EE and DP were reported. This suggests the need for research into the aspects of supervision that are deemed to be effective and to seek ways to embed enhancements, based on evidence, into the supervisory relationship.

While our comparison of two groups of social workers was revealing in terms of the substantial overlap between these groups, this study suggests the value of considering learning disability social work separately from other parts of the profession. This is not to argue that it is consistently different but to provide evidence of where problems and achievements are commonly shared or particularly distinctive. One key finding is the low proportion of responding social workers working with adults with learning disabilities who scored highly in DP, the lowest percentage compared to other user group specialisms. Levels of PA were also high despite high levels of EE; but interestingly very similar to other respondents, even those working in areas of the profession where there are frequent mentions of low morale and consequent high turnover (Bowyer \& Roe, 2015). The key differences lie in the slightly lower levels of EE among the adult learning disability respondents 
compared to those working in child protection. Importantly, the EE levels were still high and suggest that social work with adults with learning disabilities itself has stresses that should be acknowledged, explored and ameliorated. Workload is a major problem in social work and the current paper highlights concerns relating to caseload size and an absence of workload weighting to at least measure this important factor. Children's social work tends to have an acceptance that workload levels are related to risk management in casework but this is largely absent in adult social work. The current paper suggests that workload weighting is indeed generally absent across both adults and children's social work but smaller caseload numbers are present in child protection compared to learning disability social work. We acknowledge that size of 'caseload' alone is not the best measurement of risk and complexity within cases; however, in the absence of any form of caseload weighting, workers are at risk of having workloads that they struggle to manage. Workload has a major impact on wellbeing, feelings of working within or beyond capacity which seem likely to impact on the quality of service delivered. This may be particularly so if the worker is experiencing EE which can lead to a reduction in the capacity for empathy or depersonalisation.

The Chief Social Worker for England (Romeo, 2016) has expressed interest in Government consultation proposals that there should be a named social worker for people with learning disabilities and complex needs (defined as autism and mental health problems) (Department of Health, 2015). This role might provide a single point of contact for individuals and their families and enable professional challenge throughout the health and care system (as called for by Heron \& Lymbery, 2002). The British Association of Social Workers (BASW) has also welcomed this new named role, saying:

Social workers are uniquely placed to be the link between home, communities and any residential, or supported living placements. Social workers are trained and skilled in assessing, understanding and supporting people within their socio / psychological/ community context. We have at the heart of practice a social model of disability that can act as a real challenge to a medical model of illness that is very restrictive in its understanding of the 
impact of the "social" on behaviour and personal development. (BASW, 2015, p.2)

Our findings are relevant to these debates. First any such new role, which may be for a minority of learning disability social workers, will need to consider how it can be both personally accomplishing and not emotionally exhausting (to use Maslach terms). For social workers who do not have this greater status will there be a future for them? The profile of social workers working with adults with learning disabilities responding to this survey revealed that many were older than other frontline social workers. This potentially indicates a loss of experience as they move to retire but also raises questions about why younger social workers are not being attracted to or being employed in this area of practice. Are older social workers staying put in a familiar specialism for lack of opportunity or is specialist practice valued at the end of a professional career? Our findings on the lack of supervision available to our respondents working with adults with learning disabilities may suggest that they are seen as capable and a 'safe pair of hands'; this is may be need to be taken into account in respect of new or inexperienced social workers moving to this specialism. The implications for child protection social work are also stark - these is a group of often younger and sometimes inexperienced staff - but these points have been made by others in several contexts (see Hussein et al 2014a; 2014b). For social work regulators this analysis suggests the potential for asking registrants about their area of practice and their main user group(s).

\section{Conclusion}

There are few opportunities to compare social work in different specialisms. This analysis has identified commonalities and differences that were found across a national UK sample. It suggests that social work remains a rewarding but stressful profession. In light of changing professional roles it further offers a baseline for other studies. The current paper highlights that despite academic, media and political debate tending to focus on child protection workforce concerns, there is also evidence that other areas of social work share similar and yet distinct challenges.

While the study has limitations (as discussed), it offers valuable insight into the experiences of social work across a range of settings and provides food for thought 
on consistent levels of personal accomplishment in this profession despite the challenges experienced. Further research is required to ascertain the factors that provide this level of personal accomplishment, despite levels of exhaustion and depersonalisation, and to build on this baseline study.

\section{Acknowledgments and disclaimer}

We would like to thank the social workers who participated in the study and Community Care (c) that commissioned this research. We would also like to thank Anna Taller for her observation and feedback relating to the statistical analysis strategy. The views expressed in this paper are those of the authors alone and should not be taken as necessarily reflecting those of the Department of Health whose Policy Research Programme supported the contribution of Prof Manthorpe to this paper.

\section{Caption Legends for Figures and Tables}

\section{Figure 1 .}

Comparison of percentage child protection and learning disability respondents by demographics

\section{Figure 2.}

Percentages of social workers reporting on statutory social status, being practice teachers and qualified in the UK. Also levels of work experience by type of social work service.

\section{Figure 3 .}

Percentages of social workers reporting that caseload weighting is applied, whether managed by a social worker and on supervision frequency and effectiveness by type of service. 
Table $1 \mathrm{MBI}$ Items (Maslach, et al, 1996)

Table 2 MBI Subscale Cut off Points (Maslach et al., 1996)

Table 3: Emotional Exhaustion (EE) Cut Offs for child protection social workers $(n=358)$ and social workers working with adults with learning disabilities $(n=71)$

Table 4: Depersonalisation (DP) Cut Offs for child protection social workers $(n=358)$ and social workers working with adults learning disabilities $(n=71)$

Table 5 Personal Accomplishment (PA) Cut Offs for child protection social workers $(n=358)$ and social workers working with adults learning disabilities $(n=71)$

\section{References}

Bowyer, S. and Roe, A. (2015) Social Work Recruitment and Retention, Totnes, Research in Practice, https://www.rip.org.uk/resources/publications/strategic-briefings/social-workrecruitment-and-retention-strategic-briefing-open-access-download-2015 (accessed 29 May 2016)

Bigby, C. and Frowley, P. (2009) Social Work Practice with Intellectual Disability: Working to Support Change, London, Macmillan.

British Association of Social Workers (BASW) (2015) BASW response to the Green Paper "No Voice Unheard". Birmingham, BASW, http://cdn.basw.co.uk/upload/basw 102715-1.pdf

Cambridge, P. (2008) The Case for a New 'Case' Management in Services for People with Learning Disabilities, British Journal of Social Work 38 (1), 91-116.

Chou, Y-C., Kröger, T. and Lee, Y-C. (2010) Predictors of Job Satisfaction among Staff in Residential Settings for Persons with Intellectual Disabilities: A Comparison between Three Residential Models, Journal of Applied Research in Intellectual Disabilities, 23, 279-89. 
Chung, M.C. and Harding, C. (2009) Investigating Burnout and Psychological Well-Being of Staff Working with People with Intellectual Disabilities and Challenging Behaviour: The Role of Personality, Journal of Applied Research in Intellectual Disabilities, 22(6), 549-60.

Department of Health (2001) Valuing People, A New Strategy for Learning Disability for the 21st Century, London, Department of Health.

Department of Health (2015) No Voice Unheard, No Right Ignored - a consultation for people with learning disabilities, autism and mental health conditions, London, Department of Health

https://www.gov.uk/government/uploads/system/uploads/attachment data/file/409816/Docu $\underline{\text { ment.pdf }}$

Department of Personal Social Services and Public Safety Northern Ireland (DPSSPSNI) (2006) Personal Social Services Development and Training Strategy 2006-2016, Belfast, DPSSPSNI, http://niscc.info/storage/resources/2006 pss trainingstrategy.pdf

Devereux, J., Hastings, R. and Noone, S. (2009) Staff Stress and Burnout in Intellectual Disability Services: Work Stress Theory and its Application, Journal of Applied Research in Intellectual Disabilities, 22 (6), 651-73.

Duffy, S. (2010): "The citizenship theory of social justice: exploring the meaning of personalisation for social workers, Journal of Social Work Practice 24(3) 253-267.

Dyer, S. and Quine, L. (1998) Predictors of Job Satisfaction and Burnout Among the Direct Care Staff of a Community Learning Disability Service. Journal of Applied Research in Intellectual Disabilities, 11: 320-332.

Emerson, E., Hatton, C., Robertson, J., Roberts, H., Baines, S., Evison, F. and Glover. G. (2011) People with Learning Disabilities in England. London, Department of Health,

Evans S., Huxley, P., Gately, G., Webber, W., Mears, A., Pajak, S., Medina, J., Kendall, T. and Katona, C. (2005) Mental health, burnout and job satisfaction among mental health social workers in England and Wales, British Journal of Psychiatry, 188 (1) 75-80. 
Ford, J. and Honnor, J. (2000) Job satisfaction of community residential staff serving individuals with severe intellectual disabilities, Journal of Intellectual and Developmental Disability, 25(4), 343-62

Gibbs, J. (2009) Changing the cultural story in child protection: Learning from the insider's experience. Child and Family Social Work, 14(3), 289-299.

Geurts, S., Schaufeli, W. and de Jonge, J. (1998) Burnout and intention to leave among mental health-care professionals: a social psychological approach, Journal of Social and Clinical Psychology, 17(3), 341- 62.

Hatton, C., E. Emerson, E., M. Rivers, M., H. Mason, H., L. Mason, L., Swarbrick, R., Kiernan, C., Reeves, D. and Alborz, A. (1999) Factors associated with staff stress and work satisfaction in services for people with intellectual disability, Journal of Intellectual Disability Research, 43(4), 253-267.

Harries, J., Ng, K., Wilson, L., Kirby, N. and Ford, J. (2015) Evaluation of the Work Safety and Psychosocial Wellbeing of Disability Support Workers, Australasian Journal of Organisational Psychology, 8(e9), 1-13.

Hastings, RP., Horne, S. and Mitchell, G. (2004) Burnout in direct care staff in intellectual disability services: a factor analytic study of the Maslach Burnout Inventory, Journal of Intellectual Disability Research, 48(3), 268-73.

Healy, K., Meagher, G., \& Cullin, J. (2009) Retaining novices to become expert child protection practitioners: Creating career pathways in direct practice. British Journal of Social Work, 39(2), 299-317.

Herod, J, and Lymbery, M. (2002) The Social Work Role in Multi-disciplinary Teams, Practice, 14(4), 17-27.

Hickey, R. (2014) When the Desire to Do Good Makes You Feel Bad: Quality Indicators and Worker Stress, Journal on Developmental Disabilities, 20(2), 78-88.

Horner, N. (2012) What is social work? London, Learning Matters/Sage, 
House of Commons (1991) Care of persons with a mental handicap or mental illness in Scotland, London, House of Commons,

https://www.gov.uk/government/uploads/system/uploads/attachment data/file/235771/0122. $\underline{\mathrm{pdf}}$

HSCIC (2016) Personal Social Services: Staff of Social Services Departments, England, As at September 2015, Leeds, HSCIC, http://www.hscic.gov.uk/catalogue/PUB19985/pss-staffeng-15-rpt.pdf

Hunter, S. and Rowley, D. (2015) Social work with people with learning difficulties: Making a difference, Bristol, Policy Press. https://policypress.co.uk/social-work-with-people-withlearning-difficulties

Hussein, S., Moriarty, J. Stevens, M., Sharpe, E. \& Manthorpe, J. (2014a) Organisational factors, job satisfaction and intention to leave among newly qualified social workers in England, Social Work Education, An International Journal. 33 (3): 381-396.

Hussein, S., Manthorpe, J., Ridley, J., Austerberry, H., Ferrelly, N., Larkins, C., Bilson, A. and Stanley, N. (2014b) Independent Children's Social Work Practice Pilots: Evaluating Practitioners' Job Control and Burnout, Research on Social Work Practice. 24(2): 224-234.

Innstrand, S.T., Espnes, G.A. and Mykletun, R. (2002) Burnout among people working with intellectually disabled persons: a theory update and an example, Scandinavian Journal of Caring Sciences, 16(3) 272-413.

International Federation of Social Workers (IFSW) (2012) Policies: People with Disabilities http://ifsw.org/policies/people-with-disabilities/

Jones, R. (2014) The best of times, the worst of times: social work and its moment. British Journal of Social Work, 44(3) 485-502.

Kozak, A., Kersten, M., Schillmöller, Z., Nienhaus, A. (2013) Psychosocial work-related predictors and consequences of personal burnout among staff working with people with intellectual disabilities, Research in Developmental Disabilities, 34(1) 102-15. 
Leyin, A. and Wakerly, E. (2007) Staff Support, Staff Stress and Job Satisfaction in Working with People with Learning Disabilities and Challenging Behaviours, Tizard Learning Disability Review, 12(4) 31-41.

Lundstrom, M., Åstrom, S. and Granheim, U.H. (2007) Caregivers' experiences of exposure to violence in services for people with learning disabilities, Journal of Psychiatric and Mental Health Nursing, 14(4) 338-45.

Lundström, M., Graneheim, U., Eisemann, M., Richter, J. and Åström, S. (2007) Personality Impact on Experiences of Strain Among Staff Exposed to Violence in Care of People With Intellectual Disabilities, Journal of Policy and Practice in Intellectual Disabilities, 4(1), 30-39.

McAuliffe, C. (2009) Experiences of Social Workers within an Interdisciplinary Team in the Intellectual Disability Sector, Critical Social Thinking, https://www.ucc.ie/en/media/academic/appliedsocialstudies/docs/CarolMcAuliffe.pdf

Mansell, M., Beadle-Brown, J., Whelton, B., Beckett, C., Hutchinson, A. (2008) Effect of Service Structure and Organization on Staff Care Practices in Small Community Homes for People with Intellectual Disabilities, Journal of Applied Research in Intellectual Disabilities, 21(5) 398-413.

Manthorpe, J. and Martineau, S. (2015) What Can and Cannot Be Learned from Serious Case Reviews of the Care and Treatment of Adults with Learning Disabilities in England? Messages for Social Workers, British Journal of Social Work 45 (1), 331-348.

Maslach, C. and Jackson, S. (1982) Burnout in the Health Professions. A Social Psychological Analysis. In Sanders, G. and Suls, J. (Eds). Social Psychology of Health and Illness. Hillsdale, NJ: Erlbaum.

Maslach, C, and Jackson, S, (1986) Maslach Burnout Inventory Manual (2 ${ }^{\text {nd }}$ Ed.). CA: CPP, Inc. CA

Maslach, C, Jackson, S, Leiter, M, (1996) Maslach Burnout Inventory Manual (3 ${ }^{\text {rd }}$ Ed) CPP, Inc. CA 
Maslach, C. and Leiter, M. (2008) Early Predictors of Job Burnout and Engagement, Journal of Applied Psychology, 9(3), 498-512.

Munro, E. (2011) The Munro Review of Child Protection: A Child Centred System. London, Department for Education.

McFadden, P., Campbell, A., \& Taylor, B. (2014) Resilience and Burnout in Child Protection Social Work: Individual and Organizational Themes from a Systematic Literature Review. British Journal of Social Work 1-18. doi:10.1093/bjsw/bct210

McFadden, P. (2015) Measuring Burnout among UK Social Workers: A Community Care Study. Available at https://s3-eu-west-1.amazonaws.com/rbicommunities/wpcontent/uploads/sites/7/2015/07/Burnout-among-UK-social-workers.pdf McFadden, P. (2013) Resilience and Burnout In Child Protection Social Work, PhD Thesis, University of Ulster, Northern Ireland. Retrieved from http://ethos.bl.uk 9X/96/\$3.IXI82 1082

Parkin, E. (2016) Learning Disability - overview of policy and services, Briefing Paper Number 07058, London, House of Commons.

Romeo, L. (2016) Annual Report by the Chief Social Worker for Adults, London, Department of Health.

https://www.gov.uk/government/uploads/system/uploads/attachment data/file/508852/CSW AR 2015 Acc.pdf Accessed 29 January 2017

Russ, E., Lonne, B. and Darlington, Y. (2009) Using Resilience to Reconceptualise Child Protection Workforce Capacity, Australian Social Work, 62(3) 324-338. 
Sánchez-Moreno, E., La Fuente Roldán, I-R., Gallardo-Peralta, P. and Barrón López de Roda, A. (2015) Burnout, Informal Social Support and Psychological Distress among Social Workers, British Journal of Social Work 45 (8): 2368-2386.

Scottish Social Services Council (SSSC) (2016) A trusted, skilled and valued social service workforce: The work of the Scottish Social Services Council in 2015, Edinburgh, SSSC, http://www.sssc.uk.com/about-the-sssc/multimedialibrary/publications?task=document.viewdoc\&id=2445 Accessed 29 January 2017

Skirrow, P. and Hatton, C. (2007) 'Burnout' Amongst Direct Care Workers in Services for Adults with Intellectual Disabilities: A Systematic Review of Research Findings and Initial Normative Data, Journal of Applied Research in Intellectual Disabilities, 20(2) 131-44.

Smyth E., Healy O. and Lydon S. (2015) An analysis of stress, burnout, and work commitment among disability support staff in the UK, Research in Developmental Disabilities, 47, 297-305.

Vassos, M. and Nankervis, K. (2012) Investigating the importance of various individual, interpersonal, organisational and demographic variables when predicting job burnout in disability support workers, Research in Developmental Disabilities, 33(6) 1780-91.

Vassos, M., Nankervis, K., Skerry, T. and Lante, K. (2013) Work engagement and job burnout within the disability support worker population, Research in Developmental Disabilities, 34 (11) 3884-95.

Welsh Government (2015a) Guidance on Social Services and Well-being (Wales) Act 2014, Cardiff, Welsh Government, 2014http://gov.wales/docs/phhs/publications/160404part7guidevol1en.pdf

Welsh Government (2015b) SDR 165/2015, Cardiff, Welsh Government, www.gov.wales/docs/statistics/2015/151014-local

Williams, V., Boyle, G., Jepson, M., Swift, P., Williamson, T. and Heslop, P. (2014) Best interests decisions: professional practices in health and social care. Health \& Social Care in the Community, 22 (1) 78-86. 
Table $1 \mathrm{MBI}$ Items (Maslach, et al, 1996)

MBI Items (Maslach, et al., 1996)

1) I feel emotionally drained from my work (EE)

2) I feel used up at the end of the day (EE)

3) I feel tired when I get up in the morning and have to face another day at work (EE)

4) I can easily understand how clients feel about things (PA)

5) I feel I treat some clients as if they were impersonal objects. (DP)

6) Working with people all day is a real strain for me (EE)

7) I deal effectively with the problems of clients (PA)

8) I feel burned out from my work (EE)

9) I feel I am positively influencing other peoples' lives through my work (PA)

10) I have become more callous toward people since I took this job (DP)

11) I worry that this job is hardening me emotionally (DP)

12) I feel very energetic (PA)

13) I feel frustrated by my job (EE)

14) I feel I am working too hard on my job (EE)

15) I don't really care what happens to some clients (DP)

16) Working with people directly puts too much stress on me (EE)

17) I can easily create a relaxed atmosphere with clients (PA)

18) I feel exhilarated after working closely with service recipients (PA)

19) I have accomplished many worthwhile things in this job (PA)

20) I feel like I am at the end of my rope (EE)

21) In my work, I deal with emotional problems very calmly (PA)

22) I feel clients blame me for some of their problems (DP) 
Table 2: Emotional Exhaustion (EE) Cut Offs for child protection social workers $(n=358)$ and social workers working with adults with learning disabilities $(n=71)$

\begin{tabular}{|c|c|c|c|c|c|c|c|c|}
\hline & \multicolumn{6}{|c|}{ EE Cut offs } & \multirow{2}{*}{\multicolumn{2}{|c|}{ Total }} \\
\hline & \multicolumn{2}{|c|}{ Low EE } & \multicolumn{2}{|c|}{ Moderate EE } & \multicolumn{2}{|c|}{ HIGH EE } & & \\
\hline & no & $\%$ & no & $\%$ & no & $\%$ & no & $\%$ \\
\hline $\begin{array}{l}\text { Child Protection } \\
\text { (CP) }\end{array}$ & 24 & 7 & 67 & 18 & 267 & 75 & 358 & 100 \\
\hline $\begin{array}{l}\text { Adult Learning } \\
\text { Disabilities (ALD) }\end{array}$ & 9 & 13 & 13 & 18 & 49 & 69 & 71 & 100 \\
\hline & & & & & & & & \\
\hline
\end{tabular}


Table 3: Depersonalisation (DP) Cut Offs for child protection social workers ( $n=358$ ) and social workers working with adults learning disabilities $(n=71)$

\begin{tabular}{|c|c|c|c|c|c|c|c|c|}
\hline & \multicolumn{6}{|c|}{ DP Cut offs } & \multirow{2}{*}{\multicolumn{2}{|c|}{ Total }} \\
\hline & \multicolumn{2}{|c|}{ Low DP } & \multicolumn{2}{|c|}{ Moderate DP } & \multicolumn{2}{|c|}{ HIGH DP } & & \\
\hline & no & $\%$ & no & $\%$ & no & $\%$ & no & $\%$ \\
\hline Child Protection & 104 & 29.1 & 138 & 38.5 & 116 & 32.4 & 358 & 100 \\
\hline $\begin{array}{l}\text { Adult Learning } \\
\text { Disabilities }\end{array}$ & 33 & 46.5 & 27 & 38 & 11 & 15.5 & 71 & 100 \\
\hline & & & & & & & & \\
\hline
\end{tabular}


Table 4: Depersonalisation (DP) Cut Offs for child protection social workers ( $n=358$ ) and social workers working with adults learning disabilities $(n=71)$

\begin{tabular}{|c|c|c|c|c|c|c|c|c|}
\hline & \multicolumn{6}{|c|}{ DP Cut offs } & \multirow{2}{*}{\multicolumn{2}{|c|}{ Total }} \\
\hline & \multicolumn{2}{|c|}{ Low DP } & \multicolumn{2}{|c|}{ Moderate DP } & \multicolumn{2}{|c|}{ HIGH DP } & & \\
\hline & no & $\%$ & no & $\%$ & no & $\%$ & no & $\%$ \\
\hline Child Protection & 104 & 29.1 & 138 & 38.5 & 116 & 32.4 & 358 & 100 \\
\hline $\begin{array}{l}\text { Adult Learning } \\
\text { Disabilities }\end{array}$ & 33 & 46.5 & 27 & 38 & 11 & 15.5 & 71 & 100 \\
\hline & & & & & & & & \\
\hline
\end{tabular}


Table 5 Personal Accomplishment (PA) Cut Offs for child protection social workers $(n=358)$ and social workers working with adults learning disabilities $(n=71)$

\begin{tabular}{|l|l|l|l|l|l|l|l|l|l|}
\hline & \multicolumn{6}{|c|}{ PA Cut offs } & \multicolumn{2}{c|}{ Total } \\
\cline { 1 - 7 } & HIGH PA & \multicolumn{2}{|c|}{ Moderate PA } & LOW PA & \multicolumn{3}{c|}{} \\
\hline & no & $\%$ & no & $\%$ & no & $\%$ & no & $\%$ \\
\hline Child Protection & 56 & 15.6 & 134 & 37.4 & 168 & 46.9 & 358 & 100 \\
\hline $\begin{array}{l}\text { Adult Learning } \\
\text { Disabilities }\end{array}$ & 10 & 14.1 & 21 & 29.6 & 40 & 56.3 & 71 & 100 \\
\hline & & & & & & & & \\
\hline
\end{tabular}


Figure 1

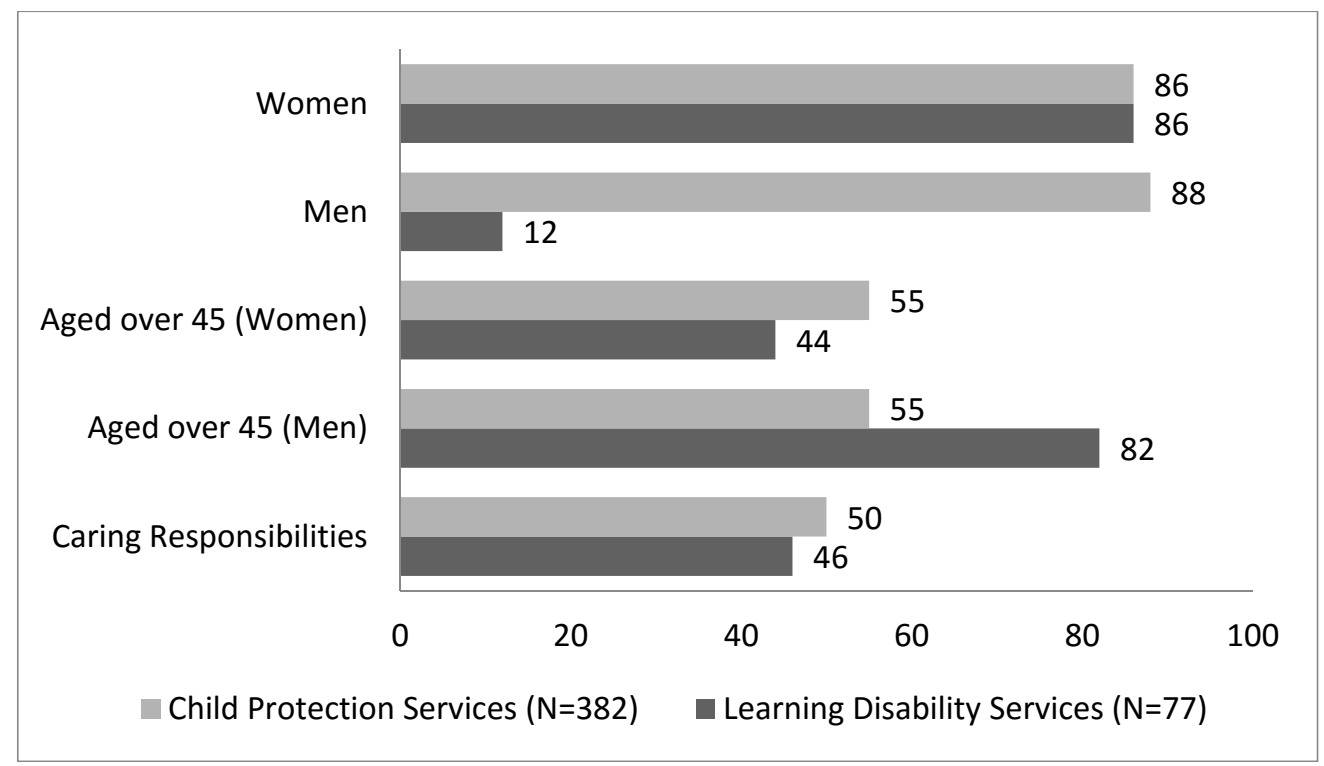

Figure 1.

Comparison of percentage child protection and learning disability respondents by demographics 
Figure 2.

Percentages of social workers reporting on statutory social status, being practice teachers and qualified in the UK. Also levels of work experience by type of social work service.

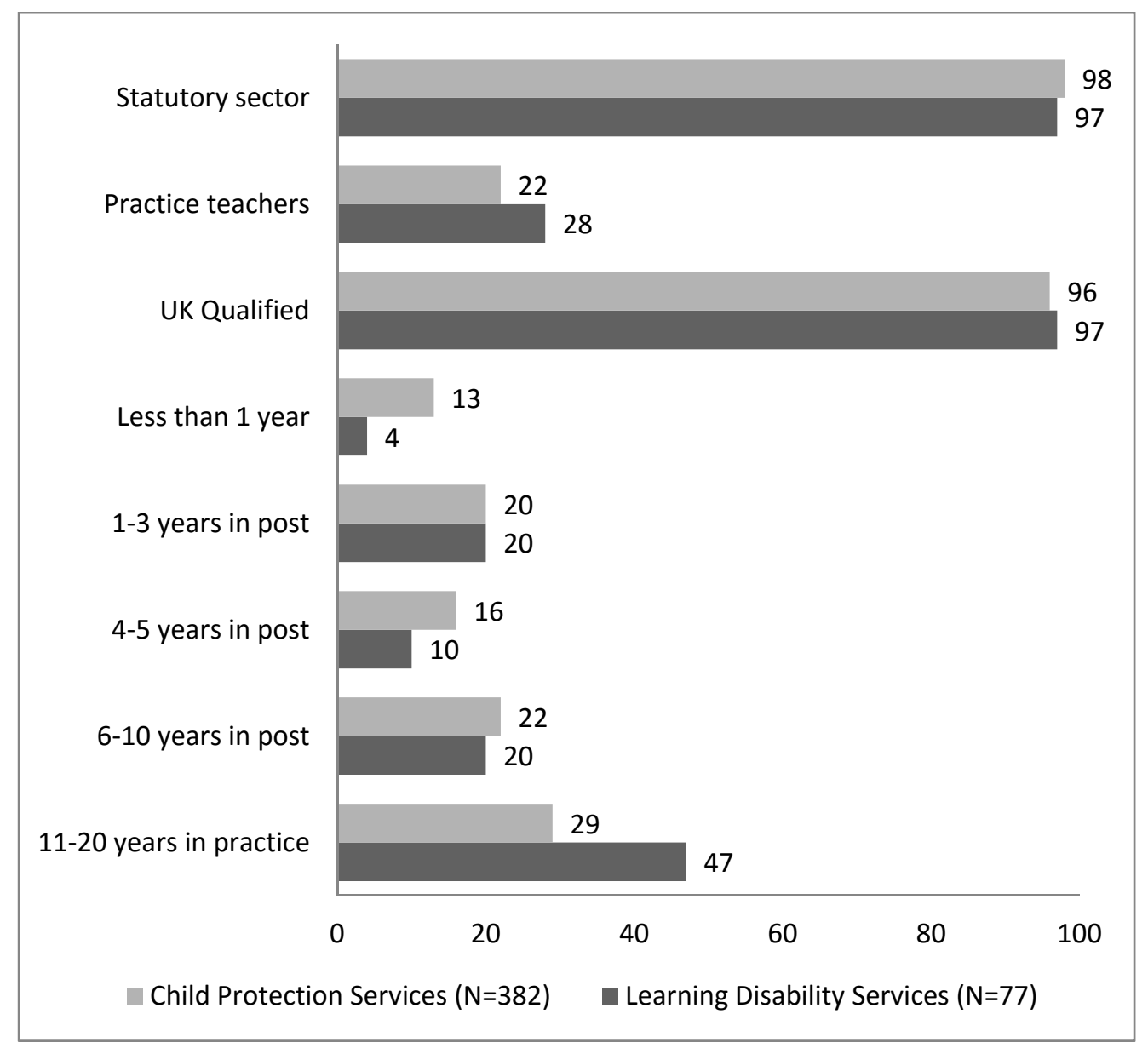

Figure 2.

Percentages of social workers reporting on statutory social status, being practice teachers and qualified in the UK. Also levels of work experience by type of social work service. 
Figure 3. Caseload weighting, social work managed and supervision.

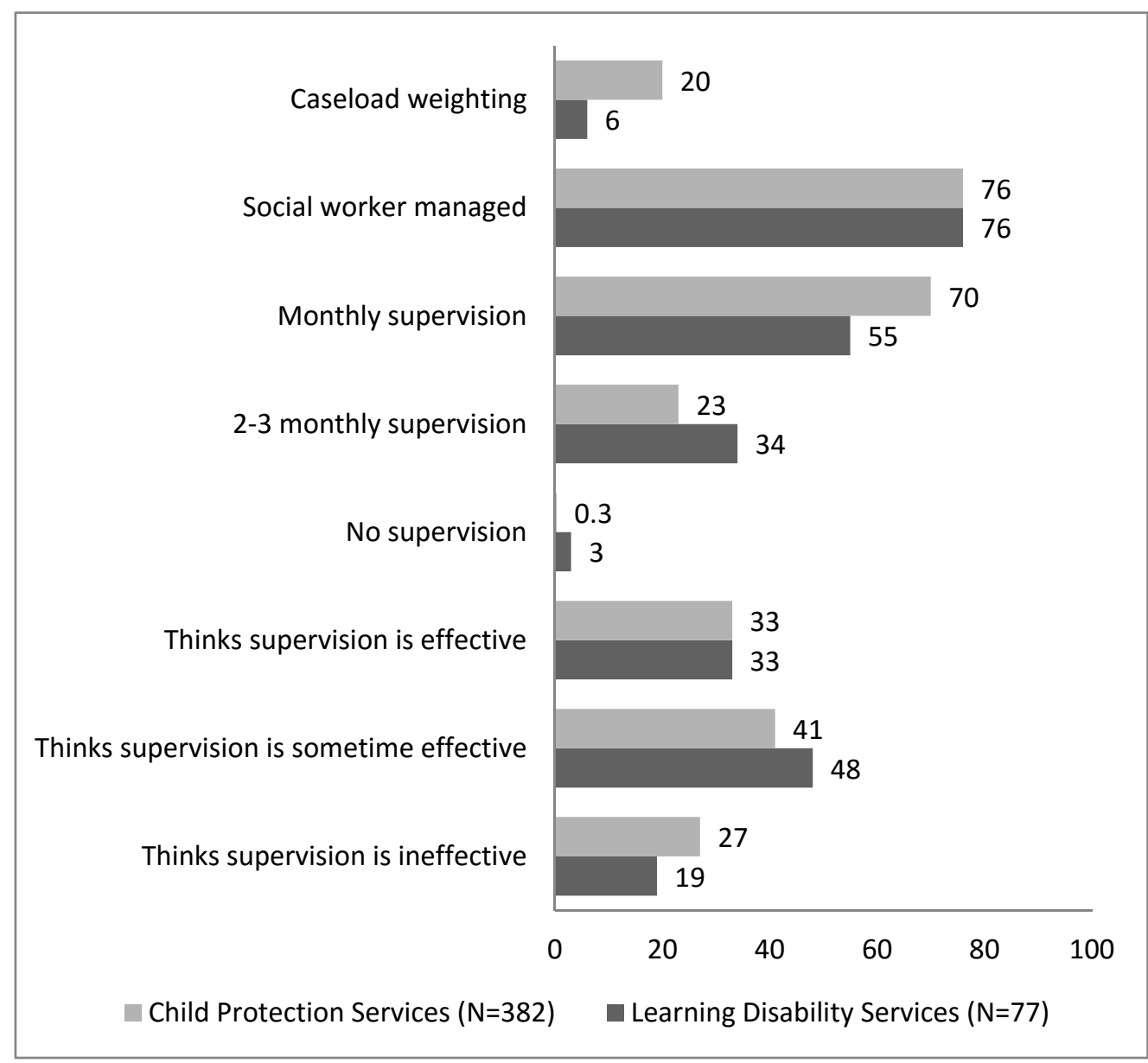

Figure 3.

Percentages of social workers reporting that caseload weighting is applied, whether managed by a social worker and on supervision frequency and effectiveness by type of service. 